distinguish outer and inner coats and in which the fibres are grouped in large spiral tufts.

The study of the morphology of the fibre types and their incidence in the various grades is not yet complete; but it seems certain that the principal types of fibres described by $D^{2}{ }^{1}$ are also found in the Australian merino.

The work of Dry and Fraser (cited by Fraser ${ }^{3}$ ) suggested that the coarse birth-coat grades of the New Zealand Romney Marsh breed were the result of a single dominant gene. This observation led us to dichotomize the data between grades 4 and 5 , and to examine the results on a 'fine' $v$. 'coarse' classification. It was postulated that the 'coarse' grades were the result of a single dominant gene and that all parents graded 'coarse' were heterozygous. Examination of pedigrees and breeding performance indicated that this latter postulate was quite reasonable. There is evidence that, as mature animals, there has been some selection against the 'coarse' grades; this selection may have been more severe against homozygous dominants. Denoting coarse grades by $A a$ (heterozygotes) and fine grades by $a a$, the accompanying table shows the results of the three possible matings.

\begin{tabular}{|c|c|c|}
\hline \multirow{2}{*}{ Mating } & \multicolumn{2}{|c|}{ Progeny grading } \\
\cline { 2 - 3 } & Coarse $(A A+A a)$ & Fine $(a a)$ \\
\hline$A a \times A a$ & 17 & 7 \\
$A a \times a a$ & 69 & 81 \\
$a a \times a a$ & 6 & 108 \\
\hline
\end{tabular}

With the exception of matings in line 3 , there is good agreement with the single dominant gene hypothesis. The occurrence of 'coarse'-coated progeny from the mating of fine-coated parents at first sight appears to invalidate the postulate. However, such a position could arise either from misgrading of animals or from complications arising from incom. plete penetrance and expressivity. As the six individuals and their parents are in grades 1,2 or 3 , misgrading is unlikely to be the cause of the discrepancy. The fact that the six individuals are all progeny of one ram suggests that the latter alternative is more probable, and that this ram, with birth. coat grade 3, had, in fact, a 'coarse' genotype. Fraser' records similar discrepancies in the Romney Marsh breed.

Observations to date on the correlation between birth-coat grade and characters of the adult fleece may be summarized as follows. Increasing birth-coat grade is associated with increasing variability of fibre diameter and decreasing number of crimps per inch; but it does not appear to be associated with mean fibre diameter. Under favourable nutritional conditions there is a close association between mean fibre diameter and crimps per inch in the fine birthcoat grades, but a much lower association in the coarse grades. There is a suggestion in our data that this association in the fine grades does not hold so strongly under conditions of poor nutritional environment.

Agricultural College,

P. G. SchinCKEL

Roseworthy,

South Australia.

June 6.

${ }^{1}$ Dry, H. W., N.Z. J. Agric., 46, 10, 141, 279 (1933).

'Dry, F. W., N.Z. J. Agric., 47, 289 (1934).

${ }^{8} \mathrm{Fraser}, \mathrm{A}$. S., thesis presented to the University of Edinburgh for the degree of Ph.D. (1950).

\section{Cultivation of Canine Hepatitis Virus in Embryonated Hen's Eggs and its Subsequent Transmission to Dogs}

VIRUs hepatitis of dogs was described by Rubarth ${ }^{1}$ in 1947 in Sweden, and since then a natural epidemic of the disease has been observed in Britain ${ }^{2}$. From the organs of two dogs dying during this epidemic, the infective agent has been cultivated by the inoculation into the yolk sac of embryonated hen's eggs for twelve successive passages, after which it was passaged back to dogs with reproduction of the disease.

Portions of the liver and lungs from the two original cases or, later, parts of the yolk sac and embryo liver were prepared as inocula by grinding with sand and mixing with broth containing 70 per cent inactivated horse serum and 7.5 per cent glucose to make a 10 per cent $\mathrm{w} / \mathrm{v}$ suspension, and storing at $-70^{\circ} \mathrm{C}$. After the addition of 500 units of penicillin and streptomycin per ml., or filtration through a 'Gradocol' membrane of average pore diameter of $640 \mathrm{~m} \mu$, $0.2 \mathrm{ml}$. of the inoculum was inoculated into the yolk sac of 6th-day embryonated hen's eggs. The firstpassage eggs were harvested on the sixth day after inoculation and no abnormalities were detected. In subsequent passages, half the four to six eggs inoculated were harvested on the sixth day thereafter and the remainder on the tenth day. In the second passage, one of four embryos died while three of the four showed hæmorrhages in the liver. With succeeding passages the proportion of deaths increased until, during the fifth passage and after, half the embryos died before the tenth day. These eggs were bacteriologically sterile on culture. From the fifth passage also nearly every embryo inoculated showed hæmorrhage and necrosis of the liver, with ascites in some cases. Macroscopically the liver lesions varied from small pale opaque areas near the lower margin to a condition approaching complete necrosis, which microscopically were confirmed as circumscribed or large areas of necrosis with either karyorrhexis or complete disappearance of the nuclei. In the areas in which hæmorrhages were present, there was evidence of necrosis of the wall of small vessels with damage to the endothelial cells. Inclusion bodies were not found.

Material from the twelfth passage was made up as a 2 per cent suspension in serum broth, filtered through a 'Gradocol' membrane of $750 \mathrm{~m} \mu$ average pore diameter and passed back to dogs by inoculating $0.05 \mathrm{ml}$. intraocularly under general anæsthesia into two seven-weeks-old greyhound pups born and reared in isolation. The reaction of these animals to inoculation was followed by clinical observations for twentyone days and by testing for specific antigen and antibodies by Larin's technique $e^{4}$.

Pup 1 showed no eye reaction, nor any clinical signs of illness for twenty-one days, but the complement fixation test demonstrated the subsequent development of specific antibodies. Pup 2 developed a marked diffuse dense central opacity of both corneas on the third day after inoculation, which decreased slowly without any vascular reaction until the eighth day. From the third to the sixth day the pup showed increasing malaise, reduced food intake and unformed stools, with a rise of temperature of less than $1^{\circ} \mathrm{F}$. The dog was destroyed when clinically convalescent on the eighth day. Macroscopically the internal organs were normal, but microscopically the liver showed vacuolation of cytoplasm and loss of nuclei in the centrilobular liver cell columns; no inclusion 
bodies were seen. Serological examination showed no antibodies in the blood, but the presence of specific antigen was detected in the liver, from which the virus was passaged to a third dog.

Liver from pup 2 stored at $-30^{\circ} \mathrm{C}$. for three months was made up as a 10 per cent $w / v$ purified suspension in saline ${ }^{3}$ and inoculated into an eightweeks-old mongrel pup No. 3 , injecting $0.05 \mathrm{ml}$. into each eye and $10 \mathrm{ml}$. intraperitoneally. The pup developed a diffuse light central opacity of both corneas on the seventh day, which disappeared in $48 \mathrm{hr}$. without any vascular reaction, coinciding with which was a morning hyperthermia of $103 \cdot 6^{\circ}-104^{\circ} \mathrm{F}$.; the dog thereafter was normal. Serological tests showed the presence of specific antigen in the blood on the ninth day and the appearance of antibodies from the twenty-eighth day onwards.

The clinical signs of systemic illness produced were mild, but quite definite; a similar syndrome, including the corneal lesions, has been observed in natural epidemics ${ }^{2}$ and in experimental infections ${ }^{3}$ of canine virus hepatitis. This diagnosis of specific virus hepatitis is supported by the detection of antibodies in the survivor of the first passage (pup 1) and of antigen in the liver of pup 2, and the confirmation of the presence of virus in this liver by the second passage inoculation into pup 3, which afterwards showed clinical illness with specific antigen and antibody in the blood.

These results show that from cases of virus hepatitis in dogs an agent can be grown in embrýonated hen's eggs after yolk-sac inoculation, and that material from the twelfth egg passage filtered through a 'Gradocol' membrane can cause the clinical disease in dogs with the occurrence of specific antigen in liver and blood and of specific antibodies in the blood.

\section{J. A. R. Miles \\ H. B. Parry \\ N. M. LARIN \\ H. Pratt}

Department of Pathology, Cambridge, and the

Canine Research Station of the Animal Health Trust, Kennett, Newmarket. April 11.

${ }^{1}$ Rubarth, S., Acta path. microbiol. Scand., Supp., 69 (1947).

${ }^{2}$ Parry, H. B., Vet. Rec., 62, 559 (1950).

${ }^{3}$ Parry, H. B., Larin, N. M., and Platt, H., J. Hyg., Camb. (in the

- Larin, N. M., J. Hyg., Camb. (in the press).

\section{Rapid Rate of Turnover of Potassium lons in Kidney Slices}

THE steady-state turnover-rate of potassium ions in guinea pig cortex slices in vitro was measured by the isotope procedure developed by Krebs, Eggleston and Terner'. There is a rapid initial loss of potassium when kidney slices are placed in physiological saline solutions, but if $0.01 M \alpha$-ketoglutarate is present, the slices reabsorb the lost potassium ${ }^{\mathbf{I}}$ and maintain the initial concentration during at least the interval from 25 to $35 \mathrm{~min}$. after the start of the incubation. When this steady state had been reached, potassium42 chloride was added to the medium and the tissue removed either two or four minutes later. Measurements were then made of the radioactivity and the potassium content of tissue and medium with a liquid counter ${ }^{2}$ and a flame photometer ${ }^{3}$. Typical results are shown in the accompanying table.

TURNover of Potassium IN KIDNey Cortex Slices

Guinea pig tissue suspended in $2 \mathrm{ml}$. bicarbonate saline containing $0.02 M$ glucose and $0.01 M$ a-ketoglutarate. Potassium- 42 chloride added after 25 min. preliminary incubation

Incubation time after addition of potassium-42 ions $2 \mathrm{~min}$.

Fresh weight of tissue

Potare incubation $\quad 17.5 \mu \mathrm{mol}$.

Potassium ions in tissue after incubation

Potassium ions in medium

Padiofore incubation

Radioactivity of medium $\left\{\begin{array}{l}\text { before incubation } \\ \text { after incubation }\end{array}\right.$

$17 \cdot 3 \mu \mathrm{mol}$.

$12 \cdot 6 \mu \mathrm{mol}$.

5,320 countsimin.

3,680 counts/min

$2 \cdot 8 \mu \mathrm{mol} . / \mathrm{min}$

Turnover of tissue potassium ions

The turnover-rate $(v / b)$ was determined from the formula :

$$
v=\frac{a b}{t(a+b)} \ln \frac{b x_{0}}{x(a+b)-a x_{0}}
$$

where $v$ is quantity of total potassium passing from tissue to medium, and in the opposite direction, per unit time; $a$ is quantity of total potassium in medium ; $b$ is quantity of total potassium in tissue ; $x_{0}$ is quantity of potassium-42 added to the medium at time $t=0 ; x$ is quantity of potassium-42 in medium at time $t$.

The average rate of turnover from eight experiments was 15 per cent/min. This means that an amount equal to the whole potassium content of the cells leaks out, and is absorbed against a concentration gradient, about every seven minutes. This rate of nine times an hour or more than two hundred times a day is the fastest so far found, being nearly twice that in retina ${ }^{1}$, four times that in brain ${ }^{1}$ and about five hundred times that in red blood cells ${ }^{4-6}$.

A full account of this work will be submitted for publication in the Biochemical Journal:

$$
\begin{aligned}
& \text { R. E. Davies } \\
& \text { A. W. Galston* }
\end{aligned}
$$

Medical Research Council Unit

for Research in Cell Metabolism,

Department of Biochemistry, University of Sheffield. July 2.

* John Simon Guggenheim Memorial Fellow.

${ }^{1}$ Krebs, H. A., Eggleston, L. V., and Terner, C., Biochem. J., 48, 530 (1951).

${ }^{2}$ Veall, N., Brit. J. Radiol., 21, 347 (1948),

${ }^{3}$ Domingo, W. R., and Klyne, W., Biochem. J., 45, 400 (1949),

${ }^{4}$ Raker, J. W., Taylor, I. M., Weller, J. M., and Hastings, A. B., J. Gen. Physiol., 33, 691 (1950).

${ }^{5}$ Sheppard, C. W., and Martin, W. R., J. Gen. Physiol., 33, 703 (1950).

'Solomon, A. K., 18th Int. Congr. Physiol., Abstr., 460 (1950).

\section{Non-adaptive Characters in Evolution}

IN a recent communication ${ }^{1}$, Dr. A. J. Cain holds that we must now accept that there is no evolution of non-adaptive--or neutral-characters in Nature. He holds this on the ground that certain characters that were previously thought to be neutral have been shown to be correlated in distribution with environmental conditions, and may therefore have some selective value. He thinks that selective value should bo assumed in all characters until the contrary is proved.

The subject is controversial; many biologists believe that much differentiation, especially of the minor or trivial differences of micro-evolution, is non- 